\title{
A QUÍMICA EM PORTUGAL TAMBÉM TEM HISTÓRIA
}

Pretendemos nestas linhas fazer um breve apanhado da luta de uma mulher, pela sua realização plena no campo profissional. Falamos da Professora Doutora Branca Edmée Marques.

Natural de Lisboa, "frequentou o único Liceu onde era ministrado o ensino a raparigas, e somente até ao fim do $5 .^{\circ}$ ano. Depois, transitou para o Liceu de Pedro Nunes, no qual, assim como no Passos Manuel, no Camões e no Gil Vicente, apenas para os $6 .^{\circ} \mathrm{e} 7 .^{\circ}$ anos aceitavam inscrições de raparigas. Em resumo, em Lisboa houve durante muitos anos quatro liceus destinados ao ensino de rapazes, e um ao de raparigas mas sem $6 .^{\circ}$ e $7 .^{\circ}$ anos.»

No Pedro Nunes, eram oito raparigas no ramo de Ciências. Destas, quatro não prosseguiram os estudos, uma foi para o Instituto Superior de Agronomia e as outras três ingressaram na Faculdade de Ciências de Lisboa e fixaram-se na Licenciatura em Ciências Físico-Químicas.

No $1 .^{\circ}$ ano da Licenciatura houve cinco raparigas e três rapazes, estes desistiram nos primeiros meses de aulas.

Das disciplinas da Licenciatura escolheram as seguintes:

i) Álgebra Superior, Geometria Analítica, Trignometria Esférica

ii) Cálculo Diferencial, Integral e das

Variaçðes

\section{Grupo das} Matemáticas

iii) Quimica Inorgânica

iv) Quimica Orgânica

v) Análise Quimica Qualitativa

vi) Análise Química Quantitativa

vii) Química-Física

O director deste grupo era o professor Achilles Machado, que fora professor do rei de Portugal, D. Manuel e do príncipe Luís Filipe.

$\begin{array}{lcc}\text { viii) Fisica dos Sólidos e dos Fluidos } & & \text { Grupo } \\ \text { ix) Acústica, Optica, Calor } & \text { da } \\ \text { x) Electricidade e Magnetismo } & \text { Física } \\ \text { xi) Curso Geral de Mineralogia e Geologia } & & \text { Grupo } \\ \text { xii) Cristalografia } & & \begin{array}{c}\text { Mineralógico } \\ \text { xiii) Geografia Física e Fisica do Globo }\end{array} \\ \text { xiv) Zoologico } \\ \text { xvia Geral } & & \\ \text { xv) Botânica Geral } & & \text { Grupo } \\ \text { xvi) Desenho de Máquinas } & & \text { das Ciências } \\ \end{array}$

As aulas, teóricas e práticas, tinham a duração de $90 \mathrm{~m}$. Havia três teóricas e três práticas semanais por cada disciplina, excepto o desenho em que havia uma aula por semana.

«Com validade para a licenciatura, os exames deviam ser pedidos pelos alunos e realizados por "grupos" e não cadeira a cadeira». As práticas e orais eram em dias
Branca Edmée Marques

- a 1. ${ }^{a}$ catedrática

de Ciências em Portugal sucessivos de uma das épocas possíveis, a de Julho ou a de Outubro.

«Como as cadeiras eram frequentadas em diferentes anos, era muito difícil vencer a licenciatura nos quatro anos marcados no horário. Mas a licenciatura em Ciências Físico-Químicas proporcionava uma sólida preparação básica, muito diversificada e, na época, era a que oferecia probabilidade maior de se encontrar colocação remunerada, quando terminada.»

A escala de classificações ia de zero a 20 valores, mas eram raras as notas de 15 valores ou superiores. No entanto, Branca Edmée Marques, obteve classificações de 17 e 19 valores ( 5 disciplinas com 19 ) o que lhe proporcionou:

1) Um convite do professor L. Pereira de Sousa (director do Grupo Mineralógico e Geológico), para 2. ${ }^{\circ}$ assistente (hoje assistente) de cadeiras desse grupo.

2) Quase simultaneamente um convite do professor Achilles Machado para o lugar de $2 .^{\circ}$ assistente efectivo de Química, portanto, para uma nomeação por haver uma vaga no quadro de docentes, para essa situação.

Terá interesse registar que Achilles Machado disse então a Branca Edmée Marques, ainda aluna, que tinha pensado muito antes de se decidir a fazer-lhe um "convite", por temer que uma senhora tão nova, não conseguisse manter a disciplina nas aulas, todas de alunos-homens. Branca Edmée Marques acrescentou que se a senhora procedesse correctamente, e esse seria o caso, os alunos seriam certamente ainda mais disciplinados do que em presença de um assistente masculino. De salientar que na época, todos os assistentes eram homens. e que a percentagem de alunas era muito pequena, na Faculdade de Ciências.

Deste modo, a entrada de Branca Edmée Marques para o "quadro docente" contribuiu para:

a) Se fixar na profissão de docente universitária,

b) e para a sucessiva entrada de outras senhoras para a situação de segundas assistentes.

Em 1930, B.E.M. solicitou a concessão de uma bolsa de estudos para no "Institut du Radium" de Paris, obter conhecimentos de Radioquímica sob a orientação de Marie Sklodowska Curie.

O Instituto de Alta Cultura, entidade oficial que concedia as bolsas, respondeu: «apresente o seu curriculum-vitae",, o que B.E.M. considerou uma negativa, pois um jovem $2 .^{\circ}$ assistente que curriculum-vitae poderia apresentar?

Em 1931, a assistente B.E.M. insistiu no pedido, e foi recebida pela sábia de renome mundial que a recebeu muito amavelmente e com a maior delicadeza perguntou-lhe: "o que sabe fazer?»

No dia seguinte, ficou instalada num grande laboratório, onde já se encontrava um romeno. Ficou incumbida de dosear o urânio numa autunite e depois numa betapite. Durante esse trabalho só lhe apareceu Mme. 
Cotelle, que era responsável junto de Mme. Curie, pelo departamento de Química Analítica.

Depois foi conduzida para o rés-do-chão da zona moderna do Instituto e ficou instalada num pequenino laboratório, junto do de Mme. Cotelle. Foi aí, e só quando podia apresentar resultados, que Mme. Curie lhe apareceu e quis ler os resultados numéricos do seu trabalho. Foi iniciada na técnica de medição de radioactividade pelo quartzo piezoeléctrico, e nas do isolamento do rádio e outros radionuclídeos.

Mme. Curie insistia sempre em ter uma ideia exacta das qualidades de investigador de cada novo estagiário. Sem disto se aperceberem, B.E.M. e o romeno Sanielevioci, estiveram a prestar provas de exame. Foi já no seu pequenino laboratório, muito agradável (por possuir uma parede toda de vidraça e portanto de grande luminosidade vista para o jardim), que Mme. Curie lhe perguntou se não preferiria um "tema de investigação". Devido à sua resposta positiva, foi-lhe fixado o do graccionamento dos sais de bário radífero. $\mathrm{E}$ ao seu critério tudo ficou: pedidos de material nas oficinas privativas, instalações, processos a seguir, etc.

Quando uma vez pediu conselho a Mme. Cotelle, ela alegremente respondeu-lhe: «Debrouilliez-vous ma chère, si cela était facile, nous l'aurions déjá fait».

$\mathrm{Na}$ época em que permaneceu no "institut du Radium" de Paris, o clima era de trabalho apaixonante que a todos contagiava. Nada de perder tempo; os sábados não eram de descanso, e alguns investigadores até voltavam ao laboratório nos domingos.

Na tarde de um sábado, Mme. Curie entrou no laboratoriozinho de B.E.M. e perguntou-lhe se poderia ir ajudá-la na tarde do dia seguinte; marcou-lhe às 14 horas. Foi mais cedo, pelas 13 horas, e perguntou ao George (ex-motorista de Mme. Curie) se a "patronne" já tinha chegado. Respondeu-lhe que estava lá desde as 8 horas. Trabalhou continuamente até às 21 horas, quando Mme. Curie lhe disse: «Acabado por hoje, talvez já esteja com fome!...». Era assim na época em que mais um prémio Nobel tinha vindo para o Instituto, concedido agora ao casal Joliot-Curie, isto é, à filha mais velha de Mme. Curie, Irene, e para o marido desta, Frederico Joliot.

Muitas vezes trabalhou para Mme. Curie, aos serões, após o jantar, para fazer medições de radioactividade, utilizando as instalações do laboratório de Mme. Curie destinado à aferição de padrões internacionais de rádio.

Nunca ela disse que desejava conseeguir um gau de "'doutor'. Foi Mme. Curie que lhe propôs que redigisse a sua Tese, que seria apreciada pelo Conselho Escolar da Universidade de Paris, e que poderia decerto realizar as provas públicas de um "Doctorat d'État", dado que o programa da licenciatura em Físico-Química (de Portugal) encontrava plenas correspondências com os programas da Universidade de Paris.

Mas Mme. Curie faleceu em 4 de Julho de 1934. O juri nomeado para as provas do doutoramento foi: professor Jean-Perrin, Frederico Joliot (ambos prémio Nobel) e professor André Debierre, directo colaborador de Mme. Curie. As provas públicas foram realizadas em 21 de Novembro de 1935. Obteve o gau de "Docteur en Sciences Physiques (doctorat d'État)" pela Universidade de Paris.

De regresso a Portugal, a doutora Branca Edmée Marques fez concurso para professora agregada da Fa- culdade de Ciências de Lisboa. As provas deste concurso eram, então, iguais às de Professor Extraordinário. Ficou aprovada por unanimidade.

Durante muitos anos, mesmo muitos, não foram abertos concursos, embora houvesse vagas a preencher.

Entretanto, conseguiu que lhe atribuíssem um" "espaço"' que transformou em laboratório, com todas as dificuldades burocráticas que se lhe deparavam. (Obras de electrificação, canalização de água, obtenção de vários aparelhos, etc.) - o que é hoje o Laboratório de Radioquímica da Faculdade de Ciências de Lisboa. Aí continuou o seu trabalho de investigação proporcionando a alguns alunos este tipo de estudos.

Por 1954, B.E.M. fez provas para a vaga de professora catedrática, deixada por Achilles Machado. Em mérito absoluto, ficou aprovada por unanimidade de votos. Mas concorrera também um alemão, das relações do filho de Achilles Machado que exercia as funções de director do departamento de Química, e foi este que foi elevado à primeira categoria. (Era homem!...)

Em 1966, por ter sido sido aberto concurso para catedrático, a professora extraordinária B.E.M. concorreu e foi, finalmente, nomeada professora catedrática. Assim, ficou sendo a primeira senhora que, nas Faculdades de Ciências de Portugal, atingiu essa posição na docência.

O atingir o último "degrau" de uma carreira não significou, no entanto, uma estagnação; uma vez que o seu trabalho continuou. De referir que ainda hoje, apesar de jubilada, frequentemente pode ser encontrada no laboratório colaborando, com algumas opiniðes, com aqueles que lá trabalham.

Do que ficou dito, se pode concluir que só com grande espirito de persistência e dedicação se poderia lutar contra tantos obstáculos que surgiam não pela falta de mérito ou competência mas sim pelo simples facto de pertencer ao sexo feminino...

Trabalho realizado por:

Ana Cristina Jesus

Cristina Oliveira

Fernando Leandro

Orientação de:

Doutora Ana Luísa Janeira

Transcrição de um texto da Prof. Branca Edmée Marques e informaçð̃es fornecidas pela própria. 